\title{
LA ACUMULACIÓN JURÍDICA COMO LÍMITE AL CUMPLIMIENTO DE CONDENA DE LOS INTERNOS
}

\author{
Carlos Díaz Martín \\ Jefe de Área Jurídica de Infancia. Jurista del Cuerpo Superior de Técnicos de \\ Instituciones Penitenciarias. Máster en Derecho de la Unión Europea
}

Resumen: Análisis de la evolución del objeto y procedimiento de la acumulación jurídica en el marco normativo y jurisprudencial y posibilidades interpretativas a futuro.

Palabras clave: Límites al cumplimiento de la pena, acumulación jurídica.

Summary: Analysis of the object and procedure to apply the serving limits in the regulatory and jurisprudential framework and its interpretative potential.

Key words: Serving limits, cumulative sentences.

\section{Introducción}

El procedimiento de acumulación de penas cuya base legal se encuentra recogida en el art. $76.2 \mathrm{CP} 10 / 1995$, de 23 de noviembre ${ }^{1}$, fue modifi-

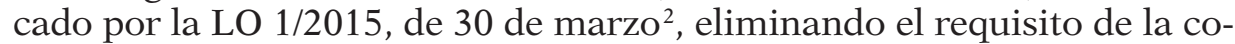
nexidad y el requerimiento de que los delitos pudieran haberse enjuiciado en solo proceso, que junto al criterio temporal, eran de forma conjunta

1 España. Ley Orgánica 10/1995, de 23 de noviembre, del Código Penal. Boletín Oficial del Estado, de 24 de noviembre de 1995, núm. 281,pp. 33987 a 34058.

2 España. Ley Orgánica 1/2015, de 30 de marzo, por la que se modifica la Ley Orgánica 10/1995, de 23 de noviembre, del Código Penal. Boletín Oficial del Estado, de 31 de marzo de 2015, núm. 77, pp. 27061 a 27176. 
los pilares sobre los que se asentaba el razonamiento jurídico que conducía el procedimiento de acumulación de penas antes de la reforma.

La acumulación jurídica siempre ha generado dudas a los operadores jurídicos, ahora bien, la entidad de los cambios legales introducidos y su desarrollo jurisprudencial y los Acuerdos del Pleno no Jurisdiccional de la Sala Segunda del Tribunal Supremo del día 3 de febrero de $2016^{3}$ (ATS) y especialmente, el ATS, de 27 de junio de $2018^{4}$, han alterado sus-

3 España.Tribunal Supremo (Pleno no Jurisdiccional de la Sala Segunda). Acuerdo del día 3 de febrero de 2016:

"La acumulación de penas deberá realizarse partiendo de la sentencia más antigua, pues al contenerse en ella los hechos enjuiciados en primer lugar, servirá de referencia respecto de los demás hechos enjuiciados en las otras sentencias. A esa condena se acumularán todas las posteriores relativas a hechos cometidos antes de esa primera sentencia.

Las condenas cuya acumulación proceda respecto de esta sentencia más antigua, ya no podrán ser objeto de posteriores operaciones de acumulación en relación con las demás sentencias restantes. Sin embargo, si la acumulación no es viable, nada impediría su reconsideración respecto de cualquiera de las sentencias posteriores, acordando su acumulación si entre sí son susceptibles de ello.

A efectos del artículo 76.2 CP hay que estar a la fecha de la sentencia en la instancia y no la de juicio.

Jurisprudencia que lo desarrolla: STS 139/2016, de 25 de febrero».

4 España.Tribunal Supremo (Pleno no Jurisdiccional de la Sala Segunda). Acuerdo del día 27 de junio de 2018:

"1. Las resoluciones sobre acumulación de condena solo serán revisables en caso de una nueva condena (o anterior no tenida en cuenta).

2. La nulidad como solución al recurso casacional, debe evitarse cuando sea dable conocer la solución adecuada, sin generar indefensión.

3. Cuando la sentencia inicial es absolutoria y la condena se produce ex novo en apelación o casación entonces, solo entonces, esta segunda fecha será la relevante a efectos de acumulación.

4. En la conciliación de la interpretación favorable del art. 76.2 con el art. 76.1 C.P., cabe elegir la sentencia inicial, base de la acumulación, también la última, siempre que todo el bloque cumpla el requisito cronológico exigido; pero no es dable excluir una condena intermedia del bloque que cumpla el requisito cronológico elegido.

5. Las condenas con la suspensión de la ejecución reconocida, deben incluirse en la acumulación si ello favoreciere al condenado y se considerarán las menos graves, para el sucesivo cumplimiento, de modo que resultarán extinguidas cuando se alcance el periodo máximo de cumplimiento.

Favorece al condenado, cuando la conclusión es que se extinguen, sin necesidad de estar sometidas al periodo de prueba.

6. No cabe incluir en la acumulación, el periodo de prisión sustituido por expulsión; salvo si la expulsión se frustra y se inicia o continúa a la ejecución de la pena de prisión inicial, que dará lugar a una nueva liquidación

7. La pena de multa solo se acumula una vez que ha sido transformada en responsabilidad personal subsidiaria. Ello no obsta a la acumulación condicionada cuando sea evidente el impago de la multa.

8. La pena de localización permanente, como pena privativa de libertad que es, es susceptible de acumulación con cualquier otra pena de esta naturaleza.

9. A efectos de acumulación los meses son de 30 días y los años de 365 días.

10. La competencia para el incidente de acumulación, la otorga la norma al Juez. o Tribunal que hubiera dictado la última sentencia; sin excepción alguna, por tanto, aunque fuere Juez de Instrucción (salvo en el caso del art. 801 LECrim, de 14 de 
tancialmente esta figura tradicional en nuestro derecho lo que plantea la necesidad de un análisis pormenorizado de su contenido por la importancia que la correcta aplicación de los límites al cumplimiento de las penas tiene para los internos.

El presente trabajo analizará la acumulación jurídica tratando de esclarecer en un primer momento, su definición, naturaleza y finalidad ${ }^{5}$, a modo de introducción a la materia y como base para el análisis posterior de la regulación, los Acuerdos del Pleno no Jurisdiccional de la Sala Segunda del Tribunal Supremo, la jurisprudencia actual y las posibilidades interpretativas abiertas entorno a la acumulación jurídica de penas, por la modificación del artículo $76 \mathrm{CP}$, de 23 de noviembre, operada por la LO 1/2015, de 30 de marzo ${ }^{6}$.

\section{Concepto}

Los términos acumulación y refundición se han venido utilizando de forma indistinta en la jurisprudencia si bien, tras la mención expresa del término acumulación en el nuevo art. $76.2 \mathrm{CP}$, de 23 de noviembre, resultaría conveniente a fin de evitar confusiones usar el término acumulación únicamente para referirnos al proceso derivado de la aplicación de los límites al cumplimiento efectivo de las penas y así se hará en este trabajo.

La acumulación jurídica se puede definir como el proceso judicial contradictorio destinado a aplicar los límites al cumplimiento, previstos en el art. $76.1 \mathrm{CP}$, de 23 de noviembre, sobre el conjunto de penas privativas de libertad determinadas impuestas al condenado por varios hechos delictivos, ya sea en sentencia, si fueron enjuiciados en el mismo proceso, o posteriormente por medio de auto que produce una nueva pena distinta de las anteriores, que será la que habrá de cumplirse en sustitución de las impuestas en las sentencias firmes.

Por otra parte, la acumulación material o refundición ${ }^{7}$ supone la suma aritmética de todas las penas de la misma naturaleza impuestas a un sujeto en orden a su cumplimiento sucesivo sin que estas pierdan su individualidad. En el caso de las penas de prisión, responsabilidad subsidiaria por impago de multa y localización permanente en régimen cerra-

septiembre ), aunque la pena que se imponga no sea susceptible de acumulación e incluso cuando no fuere privativa de libertad.

11. Contra los autos que resuelven los incidentes de acumulación, solo cabe recurso de casación».

5 Véase apartado II,III y IV respectivamente.

6 Véase apartados V, VI VII,VIII, XIX, XXy XI.

7 Regulada en los artículos 75 CP 10/1995, de 23 de noviembre, y 193.2 RP 190/1996, de 9 de febrero. 
do, la refundición encuentra su fundamento en el principio de ejecución única, que requiere la creación de una hoja de cálculo que aglutine todas las penas impuestas a fin de que las fechas de cumplimiento totales se tengan en cuenta en las fechas de repercusión penitenciaria $(1 / 4,1 / 2$, $2 / 3,3 / 4$ y 4/4) que servirán de hoja de ruta individual para los permisos de salida, la clasificación en grado y la aplicación de los beneficios penitenciarios durante el cumplimiento de la condena conforme al sistema de individualización científica establecido en el art. 72.1 LOGP, de 26 de septiembre ${ }^{8}$.

\section{Naturaleza de la acumulación}

La acumulación jurídica se configura como un derecho subjetivo de los internos de dimensión constitucional que encuentra su base legal en el derecho a la libertad personal consagrado en el art. 17.1 $\mathrm{CE}^{9}$.

El nacimiento de este derecho subjetivo ${ }^{10}$ se produce con la notificación de la sentencia que, en su caso, daría lugar al acortamiento de la condena en aplicación de los límites al cumplimiento del art. $76.1 \mathrm{CP}$, de 23 de noviembre. Desde ese momento puede el penado solicitar la acumulación de penas al juez o tribunal sentenciador.

En la clásica división entre materia de determinación o de ejecución de la pena establecida por el Tribunal Europeo de Derecho Humanos (TEDH), la acumulación jurídica constituye una materia de determinación de la pena dado que afecta directamente al alcance de la pena impuesta. La acumulación jurídica quedaría, por tanto, comprendida dentro del ámbito de aplicación de la prohibición de retroactividad de las penas $^{11}$ y el principio de legalidad penal consagrados en el artículo $7^{12}$ del

8 España. Ley Orgánica 1/1979, de 26 de septiembre, General Penitenciaria. Boletín Oficial del Estado, de 5 de octubre de 1979, núm. 239.

9 Constitución Española. Boletín Oficial del Estado, 29 de diciembre de 1978, núm. 311 , pp. 29313 a 29424.

10 Este derecho resulta exigible frente a la Administración Penitenciara formalmente desde la fecha en que el penado se encuentre agendado en el Centro Penitenciario para ser estudiado por la Junta de Tratamiento, momento en que el jurista de instituciones penitenciarias tiene encomendado analizar la información recogida en el expediente del recluso (art. 281.6 RP 1201/1981, de 8 de mayo) y en su caso, informarle de la posibilidad y momento más oportuno de solicitar la acumulación de penas.

11 Tribunal Europeo de Derechos Humanos (Gran Sala). Caso Del Río Prada contra España. Sentencia de 21 octubre 2013.

12 Art. 7 CEDH: Artículo 8 Derecho al respeto a la vida privada y familiar

«1. Toda persona tiene derecho al respeto de su vida privada y familiar, de su domicilio y de su correspondencia.

2. No podrá haber injerencia de la autoridad pública en el ejercicio de este derecho, sino en tanto en cuanto esta injerencia esté prevista por la ley y constituya una medida que, en una sociedad democrática, sea necesaria para la seguridad nacional, la seguridad pública, el 
Convenio para la protección de los derechos humanos y de las libertades fundamentales, hecho en Roma el 4 de noviembre de 1950 (CEDH) ${ }^{13}$.

\section{Finalidad de la acumulación}

Dentro de nuestro sistema de ejecución de las penas, la acumulación jurídica refleja la finalidad de reeducación y reinserción social atribuida a las penas privativas de libertad por el art. $25.2 \mathrm{CE}^{14}$.

Los límites al tiempo de cumplimiento efectivo de la condena tienen por finalidad relajar los excesos punitivos que pudieran resultar de la aplicación estricta del modelo de acumulación material de la distintas penas establecido en el art. $73 \mathrm{CP}$, de 23 de noviembre, ${ }^{15}$ que unido al sistema de cumplimiento sucesivo en función de su gravedad recogido en el art. 75 CP, de 23 de noviembre, serían susceptibles de extender el cumplimiento de la condena a lo largo de toda la vida del interno o incluso más allá.

Los límites al cumplimiento sirven de igual forma a las exigencias del principio de proporcionalidad de las sanciones, para evitar que puedan considerarse como inhumanas o degradantes conforme a la prohibición absoluta del art. $15 \mathrm{CE}$ cuando la suma de las penas correspondientes a los delitos cometidos alcance cantidades desorbitadas reñidas con el principio de rehabilitación de las penas susceptibles de desocializar al penado o profundizar su marginación.

El propósito del art. $76 \mathrm{CP}$, de 23 de noviembre, conforme a la interpretación ofrecida por la jurisprudencia atiende a un fin humanitario y limitativo del cumplimiento ${ }^{16}$ buscando encontrar un equilibrio entre la finalidad de reeducación y reinserción social y los otros objetivos atribuidos a las penas privativas de libertad, en concreto, la retribución y la prevención, general y especial, de las penas.

En consecuencia, la acumulación jurídica sería incongruente con estos fines cuando pueda suponer la certeza para el interno de que su

bienestar económico del país, la defensa del orden y la prevención del delito, la protección de la salud o de la moral, o la protección de los derechos y las libertades de los demás».

13 Convenio para la Protección de los Derechos Humanos y de las Libertades Fundamentales, hecho en Roma el 4 de noviembre de 1950. Boletín Oficial del Estado,de 10 de octubre de 1979, núm. 243, pp. 23564 a 23570.

14 Art. $25.2 \mathrm{CE}$ «contiene un mandato dirigido al legislador para orientar la política penal y penitenciaria y un principio interpretativo de las normas relativas a la imposición y cumplimiento de las penas privativas de libertad» STC 39/2012 de 29 marzo.

15 España.Tribunal Constitucional (Pleno). Sentencia núm.35/2014 de 27 febrero.

16 «El art 25.2 CE contiene un mandato dirigido al legislador y un principio interpretativo de las normas relativas a la imposición y cumplimiento de las penas». STC 322/2005 de 12 diciembre. En la misma línea, STS 367/2015, de 11 de junio. 
conducta no será castigada en caso de cometer otros delitos en el futuro creando un sentimiento de impunidad frente a la norma reprobable tanto jurídica como socialmente.

El procedimiento de acumulación jurídica dentro de los parámetros expresados pretende reducir la cuantía de la pena impuesta al sujeto por razones humanitarias y sirve como elemento motivador para el cambio conductual de aquél que de otro modo por la entidad de sus delitos vería frustrada sus expectativas de reinserción y seriamente obstaculizado el disfrute de los beneficios penitenciarios.

\section{La regulación de la acumulación jurídica}

La regulación de la acumulación jurídica se encuentra dividida entre el art. 76 CP, de 23 de noviembre y el art. 988 LECrim, de 14 de septiembre ${ }^{17}$ que veremos a continuación ${ }^{18}$.

El art. $76 \mathrm{CP}$, de 23 de noviembre, regula la faceta sustantiva de la acumulación jurídica estableciendo los límites al cumplimiento de la condena en un mismo proceso en su punto primero. En su inciso segundo establece requisitos adicionales si las penas se hubieran impuesto en distintos procesos judiciales para aplicar los límites al cumplimiento de condenas:

«1. No obstante lo dispuesto en el artículo anterior, el máximo de cumplimiento efectivo de la condena del culpable no podrá exceder del triple del tiempo por el que se le imponga la más grave de las penas en que haya incurrido, declarando extinguidas las que procedan desde que las ya impuestas cubran dicho máximo, que no podrá exceder de 20 años. Excepcionalmente, este límite máximo será:

a. De 25 años, cuando el sujeto haya sido condenado por dos o más delitos y alguno de ellos esté castigado por la ley con pena de prisión de hasta 20 años.

b. De 30 años, cuando el sujeto haya sido condenado por dos o más delitos y alguno de ellos esté castigado por la ley con pena de prisión superior a 20 años.

17 España. Real Decreto de 14 de septiembre de 1882 por el que se aprueba la Ley de Enjuiciamiento Criminal. Boletín Oficial del Estado, de 17 de septiembre de 1882, núm. 260.

18 Para más información sobre la regulación no vigente de la acumulación jurídica consultar García San Martín J. «La acumulacion jurídica de penas» 2Accésit del Premio Nacional Victoria Kent del año 2015. Secretaría General de Instituciones Penitenciarias. ISBN: 978-84-8150-320-3. Disponible en: http://www.interior.gob. es/documents/642317/1201664/La_acumulacion_juridica_de_penas_126160305. pdf/675a71f5-f2a8-46bb-ad5d-33baf31aa521 
c. De 40 años, cuando el sujeto haya sido condenado por dos o más delitos y, al menos, dos de ellos estén castigados por la ley con pena de prisión superior a 20 años.

d. De 40 años, cuando el sujeto haya sido condenado por dos o más delitos referentes a organizaciones y grupos terroristas y delitos de terrorismo del Capítulo VII del Título XXII del Libro II de este Código y alguno de ellos esté castigado por la ley con pena de prisión superior a 20 años.

e. Cuando el sujeto haya sido condenado por dos o más delitos y, al menos, uno de ellos esté castigado por la ley con pena de prisión permanente revisable, se estará a lo dispuesto en los artículos 92 y 78 bis.

2. La limitación se aplicará aunque las penas se hayan impuesto en distintos procesos cuando lo hayan sido por hechos cometidos antes de la fecha en que fueron enjuiciados los que, siendo objeto de acumulación, lo hubieran sido en primer lugar.»

La faceta procesal de la acumulación jurídica se proyecta en el art. 988 LECrim, de 14 de septiembre.

De lege lata los legitimados para iniciar el procedimiento son: el Ministerio Fiscal, el penado, o, de oficio, el juez o tribunal que hubiera dictado la última sentencia. El Juzgado o tribunal competente para conocer sobre el incidente de la acumulación jurídica será el que hubiere dictado la última sentencia firme y ejecutiva imponiendo una pena privativa de libertad, salvo en determinados casos en que la jurisdicción recayera sobre el Tribunal Supremo ${ }^{19}$ o el juzgado de instrucción ${ }^{20}$.

En orden a su tramitación procesal «el secretario judicial reclamará la hoja histórico-penal del Registro central de penados y rebeldes y testimonio de las sentencias condenatorias y previo dictamen del ministerio fiscal, cuando no sea el solicitante, el juez o tribunal dictará auto en el que se relacionarán todas las penas impuestas al reo, determinando el máximo de cumplimiento de las mismas».

Por último, se limitan los recursos contra el auto de acumulación al recurso de casación por infracción de ley que será el único que puedan interponer el ministerio fiscal y el interesado.

19 En tal caso conocerá la Audiencia que dictó la sentencia casada permitiendo así la interposición de recurso por infracción de la ley conforme a la CFGE 1/2014, de 5 de diciembre,.pág. 7. Accesible en: https:/www.fiscal.es/memorias/estudio2016/CIR/ CIR_01_2014.html

20 Artículo 801.4 LECrim, de 14 de septiembre, "Dictada sentencia de conformidad el Secretario judicial seguidamente las actuaciones junto con la sentencia redactada al Juzgado de lo Penal que corresponda, que continuará su ejecución». 


\section{El objeto de la acumulación jurídica}

El objeto de la acumulación se conforma con las penas privativas de libertad previstas en el art. $35 \mathrm{CP}$, de 23 de noviembre: de prisión, siempre y cuando hayan sido impuestas a tenor del mismo Código Penal; de responsabilidad subsidiaria por impago de multa y/o de localización permanente.

La pena de prisión permanente revisable por su naturaleza indefinida no podrá ser objeto de acumulación ${ }^{21}$. En caso de que concurra esta pena con otras cuya suma exceda de 5 años de prisión se impondrá un período de seguridad reforzado para acceder al tercer grado y a la libertada condicional conforme a lo previsto en el art. 78 bis CP, de 23 de noviembre ${ }^{22}$.

Sin embargo, señalar que judicial y doctrinalmente se ha planteado la posibilidad de extender los límites ordinarios a penas de naturaleza distinta a la privativa de libertad por razones sistemáticas. En este sentido, véase el auto de la Sección $2^{\text {a }}$ de la Sala de lo Penal de la AN de 28 de junio de 2012 -Rec. 99/2012- que considera aplicable el art. 76.2 CP, de 23 de noviembre, a penas distintas a las de prisión que sean de imposible

21 España. Tribunal Supremo (Sala de lo Penal, Sección $1^{\text {a }}$ ). Sentencia núm.488/2015, de 22 julio.

22 Artículo 78 bis CP 10/11995, de 23 de noviembre:

"1. Cuando el sujeto haya sido condenado por dos o más delitos y, al menos, uno de ellos esté castigado por la ley con pena de prisión permanente revisable, la progresión a tercer grado requerirá del cumplimiento:

a) de un mínimo de dieciocho años de prisión, cuando el penado lo haya sido por varios delitos, uno de ellos esté castigado con pena de prisión permanente revisable y el resto de las penas impuestas sumen un total que exceda de cinco años.

b) de un mínimo de veinte años de prisión, cuando el penado lo haya sido por varios delitos, uno de ellos esté castigado con una pena de prisión permanente revisable y el resto de las penas impuestas sumen un total que exceda de quince años.

c) de un mínimo de veintidós años de prisión, cuando el penado lo haya sido por varios delitos y dos o más de ellos estén castigados con una pena de prisión permanente revisable, o bien uno de ellos esté castigado con una pena de prisión permanente revisable y el resto de penas impuestas sumen un total de veinticinco años o más.

2. En estos casos, la suspensión de la ejecución del resto de la pena requerirá que el penado haya extinguido:

a) Un mínimo de veinticinco años de prisión, en los supuestos a los que se refieren las letras a) y b) del apartado anterior.

b) Un mínimo de treinta años de prisión en el de la letra c) del apartado anterior.

3. Si se tratase de delitos referentes a organizaciones y grupos terroristas y delitos de terrorismo del Capítulo VII del Título XXII del Libro II de este Código, o cometidos en el seno de organizaciones criminales, los límites mínimos de cumplimiento para el acceso al tercer grado de clasificación serán de veinticuatro años de prisión, en los supuestos a que se refieren las letras a) y b) del apartado primero, y de treinta y dos años de prisión en el de la letra c) del apartado primero.

En estos casos, la suspensión de la ejecución del resto de la pena requerirá que el penado haya extinguido un mínimo de veintiocho años de prisión, en los supuestos a que se refieren las letras a) y b) del apartado primero, y de treinta y cinco años de prisión en el de la letra b) del apartado primero». 
cumplimiento simultáneo y ello en base a la interpretación gramatical del precepto que habla de penas en general en el primer párrafo de su apartado número uno. Por otra parte, Giralt Padilla considera que el art. 76.2 $\mathrm{CP}$, de 23 de noviembre, se encuadra dentro de las «reglas especiales para la aplicación de las penas» y por analogía con el art. 74 CP, de 23 de noviembre, que no solo se aplica a las penas privativas de libertad, debería poderse extender los límites ordinarios a penas no privativas de libertad ${ }^{23}$.

Tradicionalmente las penas que no sean de prisión eran excluidas del procedimiento de acumulación, tanto las que se encontraban sustituidas por la expulsión del territorio nacional como aquellas suspendidas hasta que fueran reconvertidas en penas de prisión. Del mismo modo, se procedía con las penas de multa hasta que se acordará su sustitución por responsabilidad subsidiaria por impago. Sin embargo, conforme al ATS, de 27 de junio de 2018, se permite incluir en la acumulación las penas suspendidas si favoreciera su extinción sin necesidad de período de prueba y condicionar la inclusión de las penas de multa cuando sea evidente que se producirá el impago. Este nuevo proceder responde a criterios de economía procesal y resulta compatible con el principio de seguridad jurídica.

Por otra parte, las penas privativas de libertad que ya hubieren sido extinguidas o cumplidas deben incluirse en el procedimiento de acumulación en cuanto sus hechos pueden ser anteriores a la sentencia que determina la acumulación ${ }^{24}$.

En el caso de sentencias dictadas por un Juzgado o tribunal de un estado miembro de la Unión Europea surtirá los mismos efectos jurídicos que si hubiera sido impuesta en España si se cumple acumulativamente que los hechos fueran punibles conforme a la legislación española vigente en el momento de su comisión y si se hubiera dictado con posterioridad al 15 de agosto de $2010^{25}$. Esta limitación temporal del legislador, impuesta por la Ley Orgánica 7/2014 de 12 de noviembre ${ }^{26}$, viene a mo-

23 Giralt Padilla C. «La acumulación de condenas tras la LO 1/2015 de reforma del Código Penal. Comentario a la STS 367/2015, de 11 de junio» Diario La Ley, N ${ }^{\circ} 8616$, Sección Tribuna, 1 de Octubre de 2015, Ref. D-357, Editorial LA LEY. LA LEY 5541/2015. Pág. 3 y7.

24 España. Tribunal Supremo (Sala de lo Penal, Sección 1ª). Sentencia núm.172/2014, de 5 de marzo.

25 De conformidad con la Disposición adicional única de la Ley Orgánica 7/2014, de 12 de noviembre, que estipula que solo a partir de la fecha 15 de agosto de 2010 fijada como plazo máximo para la transposición de la Decisión marco 2008/675/JAI del Consejo, de 24 de julio de 2008, será posible el reconocimiento de resoluciones judiciales de otros países de la Unión Europea.

26 España. Ley Orgánica 7/2014 de 12 de noviembre, sobre intercambio de información de antecedentes penales y consideración de resoluciones judiciales penales en la Unión Europea. Boletín Oficial del Estado, de 13 de noviembre de 2014,núm. 27, pp. 93204 a 93214. 
dificar la interpretación anterior ${ }^{27}$ en que era posible acumular penas incluso ya cumplidas de tribunales europeos y se ha visto amparada por el Tribunal Supremo ${ }^{28}$ en la conocida como doctrina Picabea, el ATC 155/2016, de 20 de septiembre, y el STEDH, de 23 de octubre de 2018.

Sin embargo esta cuestión no es pacífica en la doctrina, SÁNCHEZ TOMÁS $^{29}$ postula la existencia de una norma penal intermedia ${ }^{30}$ por el cambio de criterio jurisprudencial del Tribunal Supremo y la posibilidad de haber aplicado la retroactividad de la doctrina reiterada de forma favorable en el periodo comprendido entre las sentencias 186/2014, de 13 de marzo y 874/2014, de 27 de enero de 2015.

En el caso de condenas a penas privativas de libertad dictadas por terceros países, para proceder a su acumulación debe existir Convenio de ejecución con el Estado extranjero en donde se juzgaron y sentenciaron los hechos ${ }^{31}$.

Las penas de localización permanente solo serán acumulables en conjunto con las anteriores cuando esta operación resulte favorable al $\mathrm{reo}^{32}$, sin perjuicio de proceder a acumular jurídicamente las distintas penas de localización permanente entre ellas. En el caso de la pena de localización permanente en su modalidad de cumplimiento en centro penitenciario, se entiende que la acumulación resultará más favorable si teniendo en cuenta la trayectoria penitenciaria del interno fuera previsible que esté disfrutara del tercer grado cuyo régimen de cumplimiento sería más favorable que el previsto en la CSGIIPP 11/2011, de 7 de julio, que regula esta modalidad de cumplimiento ${ }^{33}$.

27 Esta interpretación en favor de los derechos del reo y en ausencia de normas de trasposición de la Decisión Marco 2008/675/JAI del Consejo, de 24 de julio de 2008, relativa a la consideración de las resoluciones condenatorias entre los Estados miembros de la Unión Europea con motivo de un nuevo proceso penal se sostuvo por STS 186/2014, 13 de Marzo.

28 España. Tribunal Supremo (Sala de lo Penal, Sección 1ª). Sentencia núm.874/2014, 27 de enero de 2015.

29 Sánchez Tomás J.M. «La «doctrina» picabea (negativa a la acumulación de condenas europeas) ante el TEDH: ¿un problema de «lex mitior» intermedia? (STEDH, «as. Arrózpide Sarasola y otros c. España», 23.10.2018)». Revista Española de Derecho Europeo num.69/2019 parte Comentarios de Jurisprudencia. Editorial Civitas, SA, Pamplona. 2019. Pág. 26.

30 Téngase en cuenta que el principio de legalidad penal del art.7 CEDH comprende según el TEDH no solo la ley sino el derecho internacional, la jurisprudencia , los principios generales del derecho y la costumbre, e implica condiciones cualitativas como la accesibilidad y previsibilidad del derecho penal.

31 España. Tribunal Supremo (Sala de lo Penal, Sección $1^{\text {a }}$ ). Sentencia núm. 1129/2000, 27 de Junio.

32 Conforme a la CFGE 1/2014, de 5 de diciembre. Pág. 6.

33 España. Secretaría General de Instituciones Penitenciarias. Circular 11/2011, de 11 de julio, sobre la Pena de localización permanente en centro penitenciario. Accesible en: http:/www.institucionpenitenciaria.es/web/export/sites/default/datos/descargables/ instruccionesCirculares/CIRCULAR_11-2011_LOCALIZACION_PERMANENTE.pdf 


\section{Los límites al cumplimiento de la condena}

$\mathrm{El}$ art. $76.1 \mathrm{CP}$, de 23 de noviembre, establece dos límites ordinarios, el relativo el triple de la pena más grave y el límite absoluto de 20 años de cumplimiento efectivo de la condena. Seguidamente se concretan una serie de límites extraordinarios de 25, 30 y 40 años por la comisión de dos o más delitos conforme al art. 76.1 Ap. a), b), c) y d) CP, de 23 de noviembre. Por último, la LO 1/2015, de 30 de marzo, crea un apartado e) excluyendo la aplicación de los límites de cumplimiento a aquellos sujetos que hayan sido condenados a una pena de prisión permanente revisable.

Asimismo, es necesario aclarar que un penado puede cumplir más allá de los límites previstos en el art. $76 \mathrm{CP}$, de 23 de noviembre, cuando haya sido condenado en causas diversas y no sea posible la acumulación jurídica de las mismas ${ }^{34}$.

En todo caso, en línea con la jurisprudencia del TEDH sobre el art. 3 $\mathrm{CEDH}$, que prohíbe la tortura o penas o tratos inhumanos o degradantes, se considera que debe ser posible reducir la condena impuesta no solo por razones humanitarias, sino valorando los esfuerzos realizados por el delincuente hacia su reinserción al menos cuando este haya cumplido 25 años de condena ${ }^{35}$.

En este sentido, en el caso español la posibilidad de reducir la condena o atenuar sus efectos siempre está presente por la flexibilidad que permite nuestra regulación orientada hacia la reeducación y reinserción social de los internos. En general existe la posibilidad de solicitar un indulto en base a la Ley de 18 de junio de $1870^{36}$, si bien en el caso de reincidentes el tribunal sentenciador debe apreciar suficientes razones de justicia, equidad o conveniencia pública para su concesión. Por otra parte, en la legislación penitenciaria se recogen un entramado de instrumentos que pueden ayudar a paliar los efectos desocializadores que

34 España. Tribunal Supremo (Sala de lo Penal, Sección 1ª). Sentencia núm. 14/2014, de 21 de enero.

35 Sobre este particular la STEDH, de 9 de julio de 2013,, cita los periodos establecidos para revisar la condena previstos por la ley en treinta y dos países: Albania (25 años), Armenia (20), Austria (15), Azerbaiyán (25), Bélgica (15 con la extensión de 19 a 23 años en caso de reincidencia), Bulgaria (20), Chipre (12), República Checa (20), Dinamarca (12), Estonia (30), Finlandia (12), Francia (normalmente 18 años pero se extiende a 30 años en caso de ciertos supuestos de asesinato), Georgia (25), Alemania (15), Grecia (20), Hungría (20 a no ser que el tribunal determine otro periodo), Irlanda (se prevé una revisión inicial por la Junta Penitenciara después de cumplir 7 años de prisión, excepto en ciertos supuestos de asesinato), Italia (26), Letonia (25), Liechtenstein (15), Luxemburgo (15), Moldavia (30), Mónaco (15), Polonia (25), Rumanía (20), Rusia (25), Eslovaquia (25), Eslovenia (25), Suecia (10), Suiza (15 años reducible a 10), la antigua República Yugoslava de Macedonia (15), y Turquía (24 años, 30 en caso de pena a cadena perpetua agravada y 36 en caso de múltiples condenas a cadena perpetua agravada).

36 España. Ley de 18 de junio de 1870 estableciendo reglas para el ejercicio de la gracia de indulto. Gaceta de Madrid, de 24 de junio de 1870,núm. 175. 
acarrea el cumplimiento de una pena de prisión tales como: las salidas programadas, los permisos de salida ordinarios y extraordinarios, el principio de flexibilidad, la clasificación en tercer grado en sus distintas modalidades de cumplimiento entre las que se encuentra por medios telemáticos, la concesión de la libertad condicional y en su caso, el indulto penitenciario recogido en art. 206 RP, de 9 de febrero ${ }^{37}$.

Por otra parte, los límites al cumplimiento de condena que son materia de determinación de la pena se configuran de manera objetiva, es decir, en su aplicación los juzgados o tribunales no pueden valorar ni la efectiva reparación del daño causado a la víctima, sus familiares o a la sociedad por el delito, ni el comportamiento del penado de cara a su reinserción social, valorando la intención y la capacidad de vivir respetando la Ley penal, así como de subvenir a sus necesidades. En esta tarea deben ceñirse a aplicar los límites cuantitativos ordinarios y extraordinarios según corresponda sin que sea posible individualizar la condena en función de las circunstancias expresadas.

\section{El cálculo triple de la pena más grave}

Para determinar la pena de mayor gravedad ha de atenderse a las penas individualmente impuestas en cada sentencia ${ }^{38}$ por cada delito o falta $^{39}$ cometido. Al margen de esta regla deben quedar los supuestos concursales del art. $77 \mathrm{CP}$, de 23 de noviembre,(concursos ideal y medial), a los que se haya impuesto una pena única y los de delito continuado del art. $74 \mathrm{CP}$, de 23 de noviembre.

El triplo de la pena más grave debe fijarse sin convertir los meses a años, así por ejemplo si la pena más grave fuera de 24 meses el auto de acumulación debería fijar como pena 72 meses o 2160 días si convirtiera los meses a años con una pena 6 años o 2190 días estaría añadiendo indebidamente al monto de la condena 30 días, téngase en cuenta que penalmente los meses siempre se componen de 30 días.

37 España. Real Decreto 190/1996, de 9 de febrero, por el que se aprueba el Reglamento Penitenciario. Boletín Oficial del Estado, de 15 de febrero de 1996, núm. 40.

38 España. Tribunal Supremo (Sala de lo Penal, Sección $1^{\text {a }}$ ). Sentencia núm. 710/2014, de 7 noviembre. Marzo.

39 Delito leve con la nueva terminología tras la reforma por la LO 1/2015, de 30 de 


\section{La aplicación de los límites absolutos, ordinarios y extraordinarios}

En la concreción del límite máximo al cumplimiento efectivo de condena ha de partirse de la pena considerada en abstracto, es decir dentro del abanico penológico la pena que se hubiera podido imponer en su límite máximo.

Asimismo, hay que atender a la pena máxima imponible teniendo en cuenta las degradaciones obligatorias por el grado de ejecución del delito o en virtud de la existencia de un subtipo atenuado. Esta interpretación encuentra su fundamento en la voluntad expresa del legislador que en el art. $76.2 \mathrm{CP}$, de 23 de noviembre, no hace referencia a las penas impuestas o a aquellas en las que el culpable haya incurrido, sino, de forma más general, a aquellas con las que el delito "esté castigado por la ley», en el principio de proporcionalidad de las penas, la excepcionalidad de los supuestos y la finalidad humanitaria de las penas ${ }^{40}$.

El límite máximo de 20 años y los límites excepcionales de los supuestos a) b) c) y d) del art. $76.1 \mathrm{CP}$, de 23 de noviembre, así como el triple de la pena más grave, operan sobre las penas susceptibles de acumulación no sobre el quantum total de la condena, es decir, como hemos mencionado anteriormente ${ }^{41}$ un penado puede cumplir más allá de los límites vistos cuando haya sido condenado en causas diversas y no sea posible la acumulación jurídica entre todas ellas, sin perjuicio que se apliquen los límites en repetidas ocasiones sobre las penas susceptibles de acumulación jurídica entre sí dando lugar en su caso a varios autos de acumulación cuyas penas una vez refundidas se cumplirán sucesivamente.

\section{El auto de acumulación}

Por medio de auto ${ }^{42}$ de acumulación los jueces y tribunales sentenciadores pondrán fin al procedimiento de aplicación de los límites al cumplimiento de las penas.

La pena resultante de la acumulación jurídica constituye una nueva pena autónoma, sin perjuicio de los demás pronunciamientos de las ejecutorias acumuladas por ejemplo en relación con la responsabilidad civil.

${ }^{40}$ España. Tribunal Supremo (Sala de lo Penal, Sección 1ª). Sentencia núm.505/2015, de 20 de Julio.

${ }_{41}$ Véase apartado VII sobre los Limites al cumplimento de la condena, párrafo segundo.

42 Véase el art. 248.2 LOPJ 6/1985, de 1 de julio, que regula la forma de los autos, y el art. 120.3 CE en materia de motivación de las resoluciones, en particular cuando, como es el caso, afectan a derechos fundamentales de los concernidos por ellas. 
Esta resolución debe reflejar cual es la ejecutoria que determina la acumulación o acumulaciones a fin de que el Centro Penitenciario pueda rehacer la hoja de cálculo del penado enlazando las fechas de inicio y fin del cumplimiento de las distintas ejecutorias y solicitando al juez o tribunal que ha realizado la acumulación la liquidación correspondiente, que sustituye a las liquidaciones previas de las penas acumuladas en el auto.

La competencia para conocer de la acumulación jurídica corresponde al juez o tribunal que haya dictado la última sentencia, que deberá acordar lo que proceda respecto de la acumulación entre sí de las penas correspondientes a las restantes causas, aunque la pena haya impuesto no sea susceptible de acumulación e incluso cuando no fuera privativa de libertad, salvo en casos de sentencia de conformidad art.801 LECrim, de 14 de septiembre ${ }^{43}$.

\subsection{Contenido}

El auto de acumulación jurídica deberá contener ${ }^{44}$ :

"Los datos de las ejecutorias que se pretenden acumular, con fecha de cada sentencia definitiva y si han sido o no revisadas.

Las fechas de comisión de cada hecho delictivo;

Los delitos objeto de condena, para poder determinar después si alguno de ellos origina una limitación especial; la clase y duración de las penas impuestas. En el caso de la pena de multa debe indicarse si se ha acordado su sustitución por responsabilidad personal subsidiaria;

Por último, deben tener reflejo los términos del escrito de solicitud de acumulación y las condenas que se pretende refundir».

\subsection{La modificabilidad de los autos de acumulación}

La jurisprudencia considera que el auto de acumulación es susceptible de ampliación a nuevas responsabilidades si resultase más favorable al reo al no tener efecto de cosa juzgada ni atentar contra la intangibilidad de las resoluciones judiciales firmes.

En caso de que los hechos delictivos de una nueva causa se hubieren cometido en el período comprendido en una acumulación ya realizada la condena posterior no puede perjudicar retroactivamente. ${ }^{45}$

43 Acuerdo del Pleno no Jurisdiccional de la Sala Segunda del Tribunal Supremo de 27 de junio de 2018.

44 Siguiendo la CFGE 1/2014, de 5 de diciembre. Pág. 9.

45 España. Tribunal Supremo (Sala de lo Penal, Sección $1^{\text {a }}$ ). Sentencia núm. 226/2015 de 17 abril. 
El ATS, de 27 de junio de 2018, establece sorprendentemente que «las resoluciones sobre acumulación de condena solo serán revisables en caso de una nueva condena (o una anterior no tenida en cuenta)». Si bien pudiera parecer que se limita a reflejar una práctica bien establecida, este punto primero en relación con el cuarto en que asienta que cabe elegir «la sentencia inicial, base de la acumulación, también la última» implicaría la imposibilidad de solicitar la revisión del auto en base a esta nueva interpretación del art. $76.2 \mathrm{CP}$, de 23 de noviembre, en su redacción dada por la LO 1/2015, de 30 de marzo, que conforme a la línea jurisprudencial del Tribunal Supremo en esta materia va resultando cada vez más favorable para los internos.

En este sentido aclarar que la modificación del art. $76 \mathrm{CP}$, de 23 de noviembre, por la LO 1/2015, de 30 de marzo, resultaría aplicable a todas aquellas personas físicas que incurrieran en una actividad tipificada como delito a partir del 1 de julio del 2015, si bien en cuanto resulte más favorable teniendo en cuenta las disposiciones de ambas versiones del Código Penal en su conjunto, debería extenderse a todos aquellos condenados con anterioridad ${ }^{46}$. En este sentido, se ha pronunciado el Tribunal Supremo considerando que las normas relativas a la forma de ejecución de las penas pueden ser valoradas si repercuten en la duración temporal de las penas y su aplicación es ineludible e independiente de las circunstancias personales del penado ${ }^{47}$.

\subsection{Recursos contra el auto de acumulación}

La asistencia letrada es imprescindible en el procedimiento de acumulación de condenas a fin de garantizar los principios de contradicción, igualdad de armas y proscripción de la indefensión ${ }^{48}$, en particular para preparar la audiencia y alegar, si bien el procedimiento puede ser sido iniciado por la simple petición del interesado.

El auto de acumulación jurídica es directamente recurrible en casación sin que sea preciso el previo recurso de súplica o de reforma. Asimismo, es posible recurrir el auto por el que se rechace de plano la iniciación o incoación de un expediente de acumulación ${ }^{49}$. En todo caso, por razones de economía procesal, debe apurarse las posibilidades de $2.2 \mathrm{CP}$.

46 Disposición transitoria segunda párrafo segundo LO 1/2015, de 30 de marzo y art.

47 España. Tribunal Supremo (Sala de lo Penal, Sección 1 ${ }^{a}$ ). Sentencia núm. 1592/2017, de 27 de abril.

48 España. Tribunal Supremo (Sala de lo Penal, Sección $1^{\text {a }}$ ). Sentencia núm. 496/2015, de 24 de julio.

49 España. Tribunal Supremo (Sala de lo Penal, Sección $1^{\mathrm{a}}$ ). Sentencia núm. $651 / 2005$, de 20 de mayo. 
solucionar las omisiones en los autos a través de la aclaración (arts. 161 LECrim, de 14 de septiembre, y 267 LOPJ, de 1 de julio ${ }^{50}$ ).

\subsection{El procedimiento de acumulación jurídica de penas hasta el ATS, de 3 de Febrero de 2016.}

El procedimiento de acumulación jurídica derivaba ex lege del juego del criterio temporal y el límite en relación con los hechos delictivos de haber podido ser enjuiciados en un único proceso penal, establecidos en la letra del art. $76 \mathrm{CP}$, de 23 de noviembre, hasta la reforma por la LO 1/2015, de 30 de marzo:

"La limitación se aplicará aunque las penas se hayan impuesto en distintos procesos si los hechos, por su conexión o el momento de su comisión, pudieran haberse enjuiciado en uno sólo».

El momento procesal en que es posible acumular los distintos hechos delictivos se fue acercando por la jurisprudencia a la fecha en que se cometieron los hechos. El ATS de 29 de noviembre de $2005^{51}$ estableció que no era necesaria la firmeza de las sentencias, valorando el alargamiento del período en que sería posible la acumulación y la posible comisión de otros delitos desde que hubiera recaído la primera sentencia o definitiva hasta la sentencia firme. Y pasando a ser la fecha de la sentencia definitiva la determinante para la procedencia o no de la acumulación jurídica de penas.

Por un breve período se acepto la fecha del primer juicio oral basándose en una interpretación literal de la nueva redacción del art. $76.2 \mathrm{CP}$, de 23 de noviembre, que incluía la expresión «enjuiciamiento» si bien finalmente fue descartada por ATS, de 3 de Febrero de 2016 volviendo de nuevo a la fecha de la sentencia definitiva. Posteriormente, hay que destacar que el ATS, de 27 de junio de 2018, ha aclarado que cuando la sentencia inicial es absolutoria y la condena se produce en apelación o casación esta segunda fecha será la relevante a efectos de acumulación.

El procedimiento de acumulación para ser llevado a buen término requiere de los siguientes datos: la fecha o fechas en que se cometieron los hechos delictivos en cada causa; la fecha de las sentencias definitivas de todas las ejecutorias por las que se encuentra cumpliendo condena el interno, y conocer la naturaleza y cuantía de las distintas penas impuestas en cada proceso.

50 España.Ley Orgánica 6/1985, de 1 de julio, del Poder Judicial.Boletín Oficial del Estado, de 2 de julio de 1985, núm. 157.

51 España.Tribunal Supremo (Pleno no Jurisdiccional de la Sala Segunda). Acuerdo del día 29 de Noviembre de 2005 
La ejecución del procedimiento consiste en comprobar tomando como referencia la fecha de la sentencia definitiva más antigua si la fecha de los hechos delictivos de las otras causas son anteriores a dicha fecha, a cuyo efecto es muy deseable realizar una tabla resumen con los datos referidos más arriba ordenada desde la sentencia definitiva más antigua a la más reciente (como en el ejemplo).

Los únicos supuestos excluidos de la acumulación son los hechos que ya estuviesen sentenciados cuando se inicia el período de acumulación contemplado y los cometidos con posterioridad a la fecha de la sentencia definitiva más antigua sobre la que pivota en primer lugar el procedimiento de acumulación jurídica ${ }^{52}$.

Si no hubiera hechos anteriores a la sentencia más antigua esa causa quedará excluida del proceso de acumulación y deberá ser sumada a la pena resultante del proceso de acumulación jurídica si este fuera exitoso. En caso de que hubiera hechos no sentenciados antes de la fecha de la sentencia definitiva más antigua, procede valorar si resulta más favorable la acumulación de las penas en el período contemplado, es decir, si el resultado de la suma aritmética de las penas correspondientes a las distintas sentencias es superior o no a la aplicación de los límites de cumplimiento ordinarios y extraordinarios contemplados en el art. 76.1 $\mathrm{CP}$, de 23 de noviembre.

Seguidamente entre las restantes causas que no hayan sido consideradas para ser integradas en el primer bloque junto a la sentencia definitiva más antigua (es decir, aquellas cuyos hechos sean posteriores a la fecha de la primera sentencia definitiva o ya hubieran sido sentenciados) partiendo de la segunda sentencia más antigua se procederá de igual manera estableciéndose cuantos bloques de acumulación sean necesarios ${ }^{53}$. Cada bloque mantiene su propia autonomía y sustantividad, aplicándose los límites del art. $76 \mathrm{CP}$, de 23 de noviembre, en relación con cada uno de ellos ${ }^{54}$. Asimismo, respecto a las sentencias incluidas en cada bloque en concreto, es posible, en caso de que recayera una nueva sentencia, alterar su composición si el procedimiento de acumulación jurídica resultará más favorable al reo ${ }^{55}$.

52 Ello deriva la interpretación favorable por la Jurisprudencia del requisito de la conexidad exigida en los art.988 LECrim, de 14 de septiembre y art.76 CP CP 10/11995, de 23 de noviembre para la acumulación jurídica, al estimar que, más que la analogía o relación entre sí conforme al art. 17 y 300 LECrim, de 14 de septiembre, lo relevante es la conexidad "temporal», es decir que los hechos pudiesen haberse enjuiciado en un solo proceso, atendiendo al momento de su comisión.

53 España. Tribunal Supremo (Sala de lo Penal, Sección 1 ${ }^{\text {a)}) . ~ S e n t e n c i a ~ n u ́ m . ~ 408 / 2014, ~}$ de 14 de mayo.

54 España. Tribunal Supremo (Sala de lo Penal, Sección $1^{\text {a }}$ ). Sentencia núm. 579/2006, de 23 de mayo.

55 España. Tribunal Supremo (Sala de lo Penal, Sección $1^{\mathrm{a}}$ ). Sentencia núm. 707/2013, de 30 de septiembre . 
El proceso de acumulación descrito respondía a la lógica procesal formal acogida por la jurisprudencia del Tribunal Supremo ${ }^{56}$ que no permitía examinar todas las sentencias una a una comprobando si resultaría más favorable la acumulación y exige que el conjunto de hechos, todos ellos anteriores a una sentencia dada, formen un bloque temporal indisoluble, si bien en principio atendiendo a la redacción anterior del art. $76 \mathrm{CP}$, de 23 de noviembre, no había óbice para examinar las distintas sentencias una a una eliminando aquellas que produjeran un resultado desfavorable cumpliendo asimismo de forma estricta con el requisito de haber podido ser enjuiciados en un mismo proceso. Por ATS, de 3 de Febrero de 2016, se modificó este criterio siendo posible en los casos en que la acumulación no fuera viable por resultar perjudicial reconsiderar la inclusión de sentencias pertenecientes a ese primer bloque en relación con la segunda sentencia más antigua y así sucesivamente.

Veamos cómo se realizaría la acumulación jurídica siguiendo los criterios expresados anteriormente en el siguiente ejemplo:

\begin{tabular}{|c|c|c|c|c|}
\hline $\begin{array}{l}\text { Juzgado y } \mathbf{n}^{\mathbf{o}} \\
\text { Procedimiento }\end{array}$ & $\begin{array}{c}\text { Fecha } \\
\text { Sentencia }\end{array}$ & $\begin{array}{c}\text { Fecha } \\
\text { Hechos } \\
\text { Probados }\end{array}$ & Delito & $\begin{array}{c}\text { Pena } \\
\text { Impuesta } \\
\text { (años-meses- } \\
\text { días) }\end{array}$ \\
\hline $\begin{array}{l}1^{\circ} \text { PA 20/07 } \\
\text { Penal 2-Jaén- } \\
\text { Ej. 237/07 }\end{array}$ & $18-04-07$ & $14-07-06$ & $\begin{array}{c}\text { Robo con } \\
\text { violencia }+ \\
2 \text { faltas de } \\
\text { lesiones }\end{array}$ & $2-0-0$ \\
\hline $\begin{array}{c}2^{\circ} \text { D.U 11/09 } \\
\text {-Mixto } 2 \\
\text { Martos-Penal } \\
\text { 1-Jaén- Ej. } \\
\text { 337/09 }\end{array}$ & 25-03-09 & 18-03-09 & $\begin{array}{l}\text { Contra la } \\
\text { seguridad } \\
\text { vial }\end{array}$ & $0-4-0$ \\
\hline $\begin{array}{c}3^{\circ} \text { D.U 59/09 } \\
\text { Mixto Único } \\
\text { Priego de } \\
\text { Córdoba } \\
\text { Ej. 458/09 }\end{array}$ & 26-11-09 & $23,24-01-08$ & $\begin{array}{l}\text { Robo con } \\
\text { fuerza }\end{array}$ & $1-0-0$ \\
\hline $\begin{array}{c}4^{\circ} \text { PA 204/10 } \\
\text { Penal 4-Jaén- } \\
\text { Ej. } 451 / 10\end{array}$ & 07-09-10 & 24-03-09 & $\begin{array}{c}\text { Robo con } \\
\text { violencia en } \\
\text { tentativa }\end{array}$ & $1-0-0$ \\
\hline
\end{tabular}

56 España. Tribunal Supremo (Sala de lo Penal, Sección $1^{\text {a)}) . ~ S e n t e n c i a ~ n u ́ m . ~ 473 / 2013 ~}$ de 29 mayo. 


\begin{tabular}{|c|c|c|c|c|}
\hline $\begin{array}{l}\text { Juzgado y } \mathbf{n}^{\mathbf{0}} \\
\text { Procedimiento }\end{array}$ & $\begin{array}{c}\text { Fecha } \\
\text { Sentencia }\end{array}$ & $\begin{array}{c}\text { Fecha } \\
\text { Hechos } \\
\text { Probados }\end{array}$ & Delito & $\begin{array}{c}\text { Pena } \\
\text { Impuesta } \\
\text { (años-meses- } \\
\text { días) }\end{array}$ \\
\hline $\begin{array}{c}5^{\circ} \text { PA 15/09 } \\
\text { Penal 1-Jaén } \\
\text { Ej. 623/10 }\end{array}$ & 08-11-10 & $16-03-07$ & $\begin{array}{l}\text { Robo con } \\
\text { fuerza }\end{array}$ & $1-0-0$ \\
\hline $\begin{array}{c}6^{\circ} \text { PA 595/08 } \\
\text { Penal 2-Jaén } \\
\text { Ej. 579/10 }\end{array}$ & $09-11-10$ & $26-02-08$ & $\begin{array}{l}\text { Robo con } \\
\text { fuerza } \\
\text { en casa } \\
\text { habitada }\end{array}$ & $2-1-0$ \\
\hline $\begin{array}{c}7^{\circ} \text { PA 268/10 } \\
\text { Penal 4-Jaén } \\
\text { Ej. 87/11 }\end{array}$ & 31-01-11 & 19-03-09 & Hurto & $0-6-0$ \\
\hline $\begin{array}{c}8^{\circ} \text { PA 211/10 } \\
\text { Penal 2-Jaén } \\
\text { Ej. } 87 / 12\end{array}$ & $10-10-11$ & 17-03-09 & Hurto & $0-12-0$ \\
\hline $\begin{array}{c}9^{\circ} \text { PA 61/09 } \\
\text { Penal 1-Jaén } \\
\text { Ej. } 2 / 10\end{array}$ & $12-01-10$ & $10-12-07$ & $\begin{array}{l}\text { Robo con } \\
\text { fuerza }\end{array}$ & $1-6-0$ \\
\hline $\begin{array}{c}10^{\circ} \text { PA 7/11 } \\
\text { Penal 3-Jaén } \\
\text { Ej. 249/12 }\end{array}$ & $16-04-12$ & $\begin{array}{l}\text { enero-17 } \\
\text { feb/2008 }\end{array}$ & Receptación & $0-6-0$ \\
\hline $\begin{array}{c}11^{\circ} \text { PA 23/11 } \\
\text { Penal 1-Jaén } \\
\text { Ej. 233/12 }\end{array}$ & $11-05-12$ & 26-06-09 & $\begin{array}{l}\text { Robo con } \\
\text { fuerza }\end{array}$ & $2-0-0$ \\
\hline
\end{tabular}

En este caso la condena total es de 10-35-0. Empezando por la fecha de la sentencia más antigua que dio lugar a la Ejecutoria 237/07(1 ${ }^{\circ}$ ) 18-04-07 a esta únicamente resultaría acumulable la Ejecutoria 623/10 (5), cuyos hechos de 16-03-07 son anteriores, sin que proceda la acumulación en este primer bloque.

La segunda sentencia más antigua de fecha 25-03-09 (Ejecutoria 337/09 -2 ${ }^{\circ}$-) sería acumulable a las restantes ejecutorias, con excepción de la Ej. 233/12 $\left(11^{\circ}\right)$ cuyos hechos de 26-06-09 son posteriores. Si bien en este caso es indiferente la fecha que tiene relevancia a efectos de acumulación de 
condenas es la del último de los hechos en las Ej. 458/09 (4) y la Ej. 249/12 $\left(10^{\circ}\right)^{57}$. En este segundo bloque el triple de la pena más grave de 2-1-0 fue impuesta en la Ejecutoria 579/10 (6 ), lo que hace un total de 6-3-0 resulta más favorable para el interno que la suma de las sentencias acumulables 5-35-0. En este cálculo hay que tener en cuenta que el exceso sería de 0-1925 dado que los meses se componen de 30 dias.

Conforme al ATS, de 3 de Febrero de 2016, también sería posible acumular la Ejecutoria $623 / 10\left(5^{\circ}\right)$ en este segundo bloque al no haber resultado fructífera la acumulación en el primer bloque, y beneficiándose el interno de una reducción adicional del tiempo total internamiento de 0-35-0 por el nuevo criterio.

Por último, las penas de prisión de 2-0-0 de la Ej. 237/07 (1º) y 2-0-0 de la Ej. 233/12 $\left(11^{\circ}\right)$ deben ser refundidas con el resultado de la acumulación jurídica de 6-3-0 de prisión de la Ejecutoria 337/09 para practicar la liquidación de condena a partir del total de 10-3-0 y calcular las fechas de repercusión en el tratamiento penitenciario del penado.

\section{El procedimiento de acumulación jurídica de penas a partir del ATS, de 27 de junio de 2018}

Como ya apuntaba en un artículo anterior sobre las novedades introducidas por la LO 1/2015, de 30 de marzo, la nueva redacción otorgada al art. $76 \mathrm{CP}$, de 23 de noviembre, en que se deroga el requisito de la conexidad y la exigencia de que los hechos pudieran haber sido enjuiciados en un mismo proceso era susceptible de alterar de forma sustancial el procedimiento y resultado de la acumulación de condenas ${ }^{58}$. Sin embargo, era difícil anticipar los giros interpretativos que se han sucedido desde entonces. Veamos, la letra objeto de la discordia del apartado segundo del art. $76 \mathrm{CP}$, de 23 de noviembre:

«La limitación se aplicará aunque las penas se hayan impuesto en distintos procesos cuando lo hayan sido por hechos cometidos antes de la fecha en que fueron enjuiciados los que, siendo objeto de acumulación, lo hubieran sido en primer lugar».

Se incluye una redacción alternativa a fin de facilitar la lectura del precepto en sus propios términos:

57 España. Tribunal Supremo (Sala de lo Penal, Sección 1 ${ }^{\text {a)}) . ~ S e n t e n c i a ~ n u ́ m . ~ 628 / 2019, ~}$ de 18 de diciembre.

58 Como ya se advertía en un artículo anterior sobre la retroactividad de la reforma: Díaz Martín C. «Consecuencias jurídicas en la ejecución de las penas de prisión derivadas de la LO 1/2015». Editorial Aranzadi, SA, Cizur Menor. 2016. Revista Aranzadi Doctrinal num.2/2016 parte Comentario. Y posteriormente publicado en la obra colectiva «La ejecución de sentencias en el proceso penal», 2017, ISBN 978-84-9152-690-2, págs. 119-151. 
La limitación se aplicará aunque las penas se hayan impuesto en distintos procesos cuando lo hayan sido por hechos cometidos antes de la fecha en que fueron sentenciados los que, siendo objeto de acumulación, to hubieran sido sentenciados en primer lugar.

Por si no fuera lo suficientemente claro todavía expresamente en el art. $76 \mathrm{CP}$, de 23 de noviembre, exige para aplicar los límites al cumplimiento de penas impuestas en distintos procesos:

Partir de la sentencia incluida en primer lugar en la acumulación y que los hechos de las otras sentencias restantes sean anteriores a la referida sentencia.

El legislador elimina el requisito de la conexidad ligado al art.17 LECrim, de 14 de septiembre, en línea con la jurisprudencia que había optado por una interpretación amplia del mismo exigiendo únicamente que los hechos fueran anteriores a la sentencia definitiva. Este requisito temporal recordemos fue asumido por el legislador e introducido junto al requisito de la conexidad en el precepto por la reforma del Código Penal por la LO 7/2003, de 30 de junio ${ }^{59}$ y que en la nueva redacción se plasma en exigir que los hechos sean «anteriores». Por otra parte suprime la necesidad de que los hechos "pudieran haberse enjuiciado en uno sólo» proceso y opta por requerir que los hechos fueran anteriores a la fecha del juicio de los hechos "objeto de la acumulación», expresión que no alcanza a sustituir la redacción anterior y que añade un importante componente de incertidumbre a los requisitos para la aplicación de los límites al cumplimiento de condena.

Cabe recordar que el Tribunal Constitucional con respecto a la calidad de la ley habilitadora de las injerencias en el derecho fundamental a la libertad individual considera que la existencia de una cobertura legal expresa y clara es un requisito previo e insoslayable y mantiene que «el legislador ha de hacer el 'máximo esfuerzo posible' para garantizar la seguridad jurídica», esto es, "la expectativa razonablemente fundada del ciudadano en cuál ha de ser la actuación del poder en aplicación del Derecho «la ley debe definir las modalidades y extensión del ejercicio del poder otorgado con la suficiente claridad para aportar al individuo una protección adecuada contra la arbitrariedad» ${ }^{60}$.

Además, en este caso el Legislador no hizo expresa su voluntad en el preámbulo de la LO 1/2015, de 30 de marzo $^{61}$ en que alude únicamente de forma oblicua a la acumulación jurídica cuando dispone sobre la revisión del régimen de aplicación de las penas, «se adoptan mejoras técnicas

59 España. Ley Orgánica 7/2003, de 30 de junio, de medidas de reforma para el cumplimiento íntegro y efectivo de las penas. Boletín Oficial del Estado, de 1 de julio de 2003, núm. 156 pp. 25274 a 25278.

60 España.Tribunal Constitucional (Sala Segunda). Sentencia núm.145/2014, de 22 de septiembre.

61 Accesible en: https://www.boe.es/diario_boe/txt.php?id=BOE-A-2015-3439 
para ofrecer un sistema penal más ágil y coherente ${ }^{62}$ y nos deja con una desafortunada redacción.

El Tribunal Supremo, en la sentencia 367/2015, de 11 de junio, se pronunció sobre la modificación del precepto valorando la oscuridad de la nueva redacción y estableció que la primera sentencia es la que marca la acumulación. Esta interpretación al haber eliminado el legislador la necesidad de que los hechos pudieran haber sido enjuiciados en un solo proceso «pudiera ser perjudicial para el reo» al restringir la selección de los hechos que pudieran ofrecer una combinación más favorable. Conforme a la nueva redacción puede entenderse que en el proceso de acumulación jurídica sería posible acumular hechos ya sentenciados no susceptibles de haber sido enjuiciados en un solo proceso.

Es por ello que la expresión «objeto de acumulación» referida a los hechos que recoge la nueva redacción del art. $76 \mathrm{CP}$, de 23 de noviembre, resulta especialmente problemática ya que en principio cualquiera de los hechos delictivos de las distintas causas puede considerarse que son «objeto de acumulación» abriéndose un abanico de posibilidades en la búsqueda de cuáles deberían ser los hechos a que se refiere el artículo cuya sentencia determine la acumulación jurídica, hasta la fecha recordemos que de forma obligada se comenzaba en la sentencia más antigua a la hora de formar cuantos bloques fueran necesarios en el procedimiento de acumulación de condenas.

La interpretación del Tribunal Supremo en la mencionada sentencia $367 / 2015$, de 11 de junio en contra del reo fijando los hechos que dieron lugar a la primera sentencia como aquellos que determinan la acumulación suscita dudas por la afectación de los derechos fundamentales ineludibles a este ámbito del derecho. En un primer momento, en aplicación del principio «in dubio pro libertate» tal y como refiere el Tribunal Supremo, si bien descarta, habría que pensar en los hechos que resulten más favorables para el reo, es decir aquella sentencia que pudiera abarcar un mayor número de hechos delictivos, sin embargo rechaza este planteamiento simplista dado que generaría claramente situaciones de impunidad. En esta línea, la elección de los hechos que dieron lugar a la primera sentencia fue adoptada por el ATS de 3 de febrero de 2016, que se recoge textualmente como sigue: «La acumulación de penas deberá realizarse partiendo de la sentencia más antigua, pues al contenerse en ella los hechos enjuiciados en primer lugar, servirá de referencia respecto de los demás hechos enjuiciados en las otras sentencias. A esa condena se acumularán todas las posteriores relativas a hechos cometidos antes de esa primera sentencia». Por otro lado, este mismo acuerdo introduce una no-

62 De igual manera el art 76.2 CP 10/1995, de 23 de noviembre, paso desapercibido en el examen del anteproyecto de Ley por el Consejo de Estado que lo consideró una «mejora técnica». Véase el Dictamen del Consejo de Estado de 27 de junio de 2013, accesible en: https:/www.boe.es/buscar/doc.php?id=CE-D-2013-358 
vedad importante la posibilidad de reconsiderar sentencias pertenecientes a bloques cuyo resultado en la acumulación de un bloque anterior no hubiera resultado favorable al interno.

Posteriormente, por ATS, de 27 de junio de $2018^{63}$, se estimó que cabe elegir no solo la sentencia inicial como base de la acumulación sino también la última, siempre que todo el bloque cumpla el requisito cronológico exigido si bien no es posible excluir una condena intermedia del bloque que cumpla el requisito cronológico elegido. Es decir, la sentencia de referencia debe ser aquella de la que derive el menor gravamen para el penado ${ }^{64}$ respetando el requisito cronológico entre las sentencias que fueran «objeto de acumulación» dentro del bloque pero sin suponer que no hay bloques con sentencias anteriores que pudieran haber ofrecido un resultado favorable al penado ${ }^{65}$.

La nueva metodología a adoptar al realizar la acumulación jurídica supone una importante carga de trabajo añadida para los operadores jurídicos en aquellos casos en que el penado haya incurrido en una larga carrera delictiva, veamos como resultaría en el ejemplo que ilustra este artículo.

En el ejemplo anterior, conforme a la nueva jurisprudencia sería necesario continuar examinando las sentencias en el orden en que fueron dictadas y practicando si fueran posibles las respectivas acumulaciones a fin de decidir en última instancia cuál es la acumulación más beneficiosa. En este caso la tercera sentencia más antigua de fecha 26-11-09 (Ej. 458/09 -3 $3^{\circ}$ ) sería acumulable a todas las ejecutorias posteriores. Este nuevo bloque encabezado por la Ej. 458/09 ( $3^{\circ}$ ) en que el triple de la pena más grave es también de 6-3-0 resulta más favorable para el interno que la suma de las acumulables que en este caso se eleva a 7-31-0, suponiendo una rebaja del monto de la condena de prisión de 1-28-0 y al que se añadiría la pena de 1-0-0 de la Ejecutoria 623/10 (5') al no haber resultado fructífera la acumulación en el primer bloque, alcanzando la reducción del tiempo total internamiento 2-28-0. Por último, las penas de prisión de 2-0-0 de la Ej. 237/07 (1 $1^{\circ}$ y 0-4-0 de la Ej. 337/09 (2ª deben ser refundidas con el resultado de la acumulación jurídica de 6-3-0 de prisión, lo que hace un total de 8-7-0 y resulta más favorable que la

${ }^{63}$ El Acuerdo del Pleno no Jurisdiccional de la Sala Segunda del Tribunal Supremo de 27 de junio de 2018 en relación con la aplicación del art.76.2 CP en concreto refiere: «En la conciliación de la interpretación favorable del art. 76.2 con el art. 76.1 C.P., cabe elegir la sentencia inicial, base de la acumulación, también la última, siempre que todo el bloque cumpla el requisito cronológico exigido; pero no es dable excluir una condena intermedia del bloque que cumpla el requisito cronológico elegido».

${ }^{64}$ España. Tribunal Supremo (Sala de lo Penal, Sección 1ª). Sentencia núm. 492/2019, de 16 de octubre .

65 España. Tribunal Supremo (Sala de lo Penal, Sección $1^{\text {a }}$ ). Sentencia núm. 571/2019, de 22 de noviembre. 
acumulación que dirigía la Ej. 337/09 (2º que recordemos rebajaba la condena de prisión a 10-3-0.

Esta segunda interpretación continua ampliando el número de operaciones posibles a fin de adoptar el resultado más favorable al reo en línea con la nueva redacción más abierta del art. $76.2 \mathrm{CP}$, de 23 de noviembre, y la sentencia del Tribunal Supremo, de 22 de Julio de 1944, que afirmó «cuando la jurisprudencia ha fijado una determinada interpretación legal, debe ésta ser mantenida, en aras de la certidumbre y la seguridad de las relaciones jurídicas, en tanto no se demuestre de modo indubitable, la autonomía de ella con el verdadero contenido de la Ley». A este fin de acercarse al contenido del precepto progresivamente responde permitir elegir entre las distintas sentencias susceptibles de acumulación, aquella que dispense un resultado más favorable para el penado, como base de la acumulación, siempre que se respete tanto la no inclusión de hechos ya sentenciados como la exclusión de aquellos posteriores a esta sentencia base. Si bien este proceso de adaptación tiene un coste en términos de seguridad jurídica y de aplicación en la práctica a la población penitenciaria.

En opinión de este autor ambos cambios jurisprudenciales ${ }^{66}$ habrían sido perfectamente válidos de acuerdo a la anterior versión del art. 76.2 $\mathrm{CP}$, de 23 de noviembre, y sin embargo no alcanzan la laxitud a que apremia el art. $76.2 \mathrm{CP}$, de 23 de noviembre, con su enunciado que no exige que los hechos pudieran haber sido enjuiciados en un mismo proceso, tan solo que sean anteriores a la sentencia sobre la que pivota la acumulación de un bloque. Por otra parte, hay que destacar la labor del Tribunal Supremo flexibilizando los criterios consolidados entorno a la acumulación jurídica, a la vez que trata de mantener principios básicos, como la imposibilidad de acumular hechos ya sentenciados, aun cuando la nueva base legal no impone expresamente este principio. Como base legal alternativa bien pudiera pensarse en usar el art. 988 LECrim, de 14 de septiembre, donde figura dicho principio «condenado en distintos procesos por hechos que pudieron ser objeto de uno solo" si bien no parece apropiado en cuanto puede considerarse derogado en parte por la reforma de la LO 1/2015, de 30 de marzo y además, este artículo remite expresamente al art. $76 \mathrm{CP}$.

\section{Propuestas de futuro sobre el procedimiento de acumulación jurídica}

Según ha señalado el TEDH los derechos reconocidos en el CEDH deben interpretarse y aplicarse de manera que resulten efectivos en la prác-

66 Acuerdos del Pleno no Jurisdiccional de la Sala Segunda del Tribunal Supremo de 23 de febrero de 2016 y de 7 de junio de 2018. 
tica y no teóricos ${ }^{67}$. Nuestro Tribunal Constitucional eleva esta garantía habiendo afirmado en reiteradas ocasiones, que las normas legales deben interpretarse "de conformidad con la Constitución y en el sentido más favorable para la efectividad de los derechos fundamentales y de la correlativa interpretación restrictiva de sus limites ${ }^{68}$ » y además, el cambio jurisprudencial siempre es posible para adaptar la interpretación de las normas a nuevos supuestos de hecho si bien cuanto más consolidado este un criterio jurisprudencial más intensa debe ser la fundamentación del cambio ${ }^{69}$.

Cabe plantearse si a futuro, sino mediara una nueva modificación del precepto, el Tribunal Supremo continuará ampliando el ámbito de aplicación el art. $76.2 \mathrm{CP}$, de 23 de noviembre, en atención a la finalidad de la norma que no es otro que «reducir a un límite máximo racional la extensión de la privación de libertad de una persona ${ }^{70}$ y encontrando nuevas posiciones de equilibrio con sus limitaciones. En este sentido, señala SUBIJANA ZUNZUNEGUI ${ }^{11}$ «los poderes públicos, radicados en el espacio normativo y jurisdiccional, deben adoptar las medidas idóneas para prevenir la victimización» a través del diseño de contextos jurídicos de contención de los riesgos derivados del comportamiento del victimario.

A continuación se reproducen algunos extractos de la jurisprudencia sobre la prisión provisional por resultar de interés, por analogía, al caso objeto de estudio:

El Tribunal Supremo, como máximo intérprete de la legalidad ordinaria, se pronunció en STS 1391/2009, de 10 de diciembre, sobre el abono de la prisión provisional estimando que si bien «el derecho a la libertad puede resultar conculcado, tanto cuando se actúa bajo la cobertura improcedente de la ley, como cuando se proceda contra lo que la misma dispone», no siendo excluible "una lesión del art. 17.1 CE, si no se procede tal y como ordena el Código Penal y la Ley de Enjuiciamiento Criminal» es discutible que la omisión en el art. 58.1 CP, de 23 de noviembre, por el Legislador «necesariamente conduzca a un ajuste estricto a la literalidad del precepto» por la afectación de los principios de seguridad jurídica art. 9.3 CE), igualdad (art. 14 CE), proporcionalidad (arts.1.1, 9.3 y 10.1 CE) e incluso a la buena fe procesal( art. $24.1 \mathrm{CE})^{72}$. Estos argumentos pue-

67 Tribunal Europeo de Derechos Humanos (Gran Sala). Caso Hirsi Jamaa y otros contra Italia. Sentencia de 23 febrero 2012.

68 En este sentido STC 57/2008 de 28 abril. y STC 67/1984, de 7 de junio.

69 España. Tribunal Supremo (Sala de lo Penal, Sección 1ª). Sentencia núm. 39/2012, de 29 de marzo.

70 España. Tribunal Supremo (Sala de lo Penal, Sección $1^{\text {a }}$ ). Sentencia núm. 577/2019, de 26 de noviembre.

71 Subijana Zunzunegui, I.J. "El juez en la ejecución de las penas privativas de libertad”. Revista Electrónica de Ciencia Penal y Criminología (en línea). 2005, núm. 07-11, p. 11:1 -11:20. Pág. 3. abril.

72 España.Tribunal Constitucional (Sala Segunda). Sentencia núm.57/2008, de 28 de 
den darse por reproducidos mutatis mutandis a la situación que crea la modificación del art. $76.2 \mathrm{CP}$, de 23 de noviembre, por la escasa calidad de la ley penal.

El Tribunal Constitucional, en sentencia 92/2012, de 7 de mayo, preciso también sobre el abono de prisión provisional, que la previsión legal del art. 58.1 CP, de 23 de noviembre, en la redacción anterior a la LO $1 / 2015$, de 30 de marzo, no puede aplicarse a supuestos distintos a los que contempla y justifican la norma, dado que «una interpretación aparentemente amparada en el enunciado literal de la norma pero que desconoce su finalidad, provoca un efecto no querido por ésta; pues si el mismo tiempo de privación material de libertad se descuenta varias veces de la sanción prevista para varios hechos, la rebaja en el cumplimiento de las penas impuestas depende de una circunstancia procesal totalmente imprevisible».

En el caso de la acumulación jurídica hay que partir de que la elección entre los hechos delictivos "objeto de acumulación» que posibilita la nueva redacción del art. $76 \mathrm{CP}$, de 23 de noviembre, debe responder, tanto a la finalidad de la acumulación jurídica como a sus límites para la efectiva protección de los bienes jurídicos protegidos por el derecho penal. Por tanto, la nueva redacción en principio permite diseñar una nueva metodología al realizar la acumulación jurídica en que deben quedar excluidos del bloque aquellos hechos posteriores a la sentencia elegida y cuyo resultado determine una pena proporcional a los delitos cometidos.

Como alternativa interpretativa que revela la lectura conjunta de los apartados 1 y 2 del art. $76 \mathrm{CP}$, de 23 de noviembre, se propone elegir los hechos que dieron lugar a la pena más grave y analizar las posibles consecuencias de este cambio sustancial ${ }^{73}$.

Respecto a la finalidad de reducir los posibles excesos punitivos es evidente que si la acumulación resulta beneficiosa el resultado será inferior a la suma del total de las penas impuestas.

En lo relativo al patrimonio punitivo o «cheque en blanco» como límite de la acumulación jurídica, sería difícil de prever para el delincuente que ha cometido varios delitos el monto exacto de esa pena más grave a imponer, al tener que asumir incidentes que cambien la tipología delictiva o agraven las circunstancias de la comisión del delito o los propios derivados de las vicisitudes judiciales, estas circunstancias redundan en que resulte difícil saber de antemano en caso de continuar con la carrera delictiva cual sería la entidad de la pena a cumplir con

73 Díaz Martín C. «Consecuencias jurídicas en la ejecución de las penas de prisión derivadas de la LO 1/2015». Editorial Aranzadi, SA, Cizur Menor. 2016. Revista Aranzadi Doctrinal num.2/2016 parte Comentario. Obra Colectiva «La ejecución de sentencias en el proceso penal», 2017, págs. 119-151 
aplicación de los límites al cumplimiento de la condena del art. $76.1 \mathrm{CP}$, de 23 de noviembre, .

En el caso de que las penas impuestas en todas las causas fuera de igual cuantía esta interpretación obliga a que la acumulación la determine la causa más reciente, por ser susceptible de abarcar un mayor número de causas y resultar más favorable al reo, si bien este supuesto teórico supondría una extraordinaria rebaja en el tiempo de cumplimiento parece de difícil consecución por el delincuente en la práctica.

En cuanto a la metodología a practicar con esta interpretación sobre el ejemplo visto:

Partiendo de los hechos que dieron lugar a la pena más grave de 2-1-0 en la Ej. 579/10 (6 $6^{\circ}$ serían acumulables las 5 anteriores ejecutorias cuyos hechos son anteriores en base a que el art. 76 CP no exige que los hechos pudieran haber sido enjuiciados en un mismo proceso y 5 causas posteriores dado que sus hechos son también anteriores a la sentencia de fecha 9-11-10. Este bloque encabezado por la Ej. 579/10 (6 $6^{\circ}$ en que el triple de la pena más grave es también de 6-3-0 resulta más favorable para el interno que la suma de las acumulables que en este caso coincide con la condena total de 10-35-0 y suponen una rebaja de la condena de prisión de 4-32-0. En comparación con la jurisprudencia en vigor que recordemos era un pena de prisión de 8-7-0 en este caso supone una reducción adicional de 2-4-0.

Por otro lado, cuando esta interpretación pudiera ser admisible en casos donde los delitos sean de escasa entidad, en aquellos casos en que la carrera delictiva incluyera una serie de delitos graves o que hubieran producido una gran alarma social se plantea la posible desproporción de la condena correspondiente por la aplicación de los límites del art. 76 CP. En ese caso partiendo de la esperanza de vida media para hombres de 80 años y de 86 para las mujeres en nuestro país ${ }^{74}$ que como hemos dicho es el umbral que no debe superar la condena a cumplir, para coger perspectiva sobre a qué edad del interno sería puesto en libertad y cuantos años de vida le restarían habría que sumar la edad mínima para ser juzgado conforme al art.19 CP Código Penal de 18 años a los límites extraordinarios $(25,30$ y 40$)$, operación que ofrece los siguientes resultados: 43, 48, 58 años respectivamente, y pensar si sería aceptable desde un punto de vista del diseño de la política criminal, decisión que si bien corresponde al Legislador dada la redacción del precepto de facto ha dejado en manos del poder jurisdiccional a pesar de la afectación de los principios de seguridad jurídica, igualdad, proporcionalidad e incluso a la buena fe procesal.

74 Conforme a los datos Instituto Nacional de Estadística disponibles en: https://www. ine.es/ss/Satellite?L=es_ES\&c=INESeccion_C\&cid=1259926380048\&p=1254735110672\& pagename $=$ ProductosYServicios/PYSLayout 
Esta interpretación de la nueva redacción del art.76.2 CP permitiendo optar por la sentencia que juzgo los hechos que dieron lugar a la pena más grave eliminaría posibles efectos discriminatorios derivados de los diferentes tiempos de resolución del proceso penal por los juzgados y tribunales a lo largo del territorio nacional, que en ocasiones implicaban en el procedimiento tradicional de acumulación de condenas, que un interno dependiendo de la diligencia con que fueran juzgados sus delitos pudiera ser acreedor o no de la acumulación y por su sencillez aportaría una mayor seguridad jurídica sobre la determinación de la condena a cumplir.

A futuro bien esta $\mathrm{u}$ otras interpretaciones pueden ser aceptadas por la jurisprudencia dada la laxitud con que se redactó el art. $76.2 \mathrm{CP}$, de 23 de noviembre, y el principio de indubio pro reo, sin embargo esperemos que el legislador aprovechando alguna de la reformas que se encuentran en tramitación ${ }^{75}$ regule de forma clara y precisa a quién corresponde la acumulación de condenas, los requisitos y el procedimiento que debe seguirse para realizar esta operación, modificando tanto el art. $76 \mathrm{CP}$, de 23 de noviembre, como el artículo 988 LECRrim, de 14 de septiembre, y reforzando los principios de seguridad jurídica, igualdad, proporcionalidad y buena fe procesal en una figura como la acumulación jurídica de penas que es de vital importancia para nuestro sistema penitenciario enfocado en la reeducación y reinserción de los internos.

\section{Bibliografía}

Díaz Martín C. "Consecuencias jurídicas en la ejecución de las penas de prisión derivadas de la L.O. 1/2015», Revista Aranzadi Doctrinal num.2/2016 parte Comentario, Editorial Aranzadi, SA, Cizur Menor, 2016. Obra Colectiva «La ejecución de sentencias en el proceso penal», 2017, págs. 119-151.

FERNÁNDEZ-GaLlaRdo FernáNDEZ-GaLlaRdo, J.A. «Criterios aplicables en la acumulación de condenas», REDUR 14, diciembre 2016, págs. 31-65.

Fossas EsPadALER E. «Límites materiales al legislador penal en un espacio de pluralismo constitucional», Revista Española de Derecho Constitucional, estudios críticos, núm. 103, enero-abril (2015), págs. 305-332.

Giralt Padilla C. «La acumulación de condenas tras la LO 1/2015 de reforma del Código Penal. Comentario a la STS 367/2015, de 11 de ju-

75 Entre otros, se encuentra en tramitación el proyecto de Ley Orgánica de protección integral a la infancia y la adolescencia frente a la violencia que modifica ambos texto legales y puede consultarse en: http://www.congreso.es/public_oficiales/L14/CONG/ BOCG/A/BOCG-14-A-22-1.PDF 
nio» Diario La Ley, No 8616, Sección Tribuna, 1 de Octubre de 2015, Ref. D-357, Editorial LA LEY. LA LEY 5541/2015.

Manjón-CaBeza Olmeda A. «¿Son vinculantes los acuerdos del pleno no jurisdiccional de la sala segunda del TS?». Revista Electrónica de Ciencia Penal y Criminología, 2 de febrero de 2008.

Martín Pallín. JA. «Análisis de la sentencia de la Gran Sala del Tribunal de Estrasburgo». Actualidad Jurídica Aranzadi num.873/2013 parte Comentario. Editorial Aranzadi, SA, Pamplona. 2013.

Nistal Burón J. «El cumplimiento de las condenas no susceptibles de acumulación jurídica. problemática y soluciones posibles». Diario La Ley $\mathrm{n}^{\circ}$ 6816. Jueves, 8 de noviembre de 2007.

Nistal Burón J. «La acumulación jurídica «a futuro» de penas que aun no han sido impuestas: su justificación en el tratamiento penitenciario del penado». Diario La Ley, ISSN 1989-6913, No 8793, 2016.

Nistal Burón J. «El artículo 76 del Código Penal. Alcance de la regla de la «acumulación jurídica» (1): a propósito del Auto de la Audiencia Nacional, Sala de lo Penal, Sección 2. ${ }^{a}$ de 28 junio de 2012, rec. 99/2012», Diario La Ley, ISSN 1989-6913, No 8025, 2013.

SÁNCHEZ ToMÁs J.M. «La «doctrina» picabea (negativa a la acumulación de condenas europeas) ante el TEDH: ¿un problema de «lex mitior» intermedia? (STEDH, «as. Arrózpide Sarasola y otros c. España», 23.10.2018)», Revista Española de Derecho Europeo num.69/2019 parte Comentarios de Jurisprudencia Editorial Civitas, SA, Pamplona. 2019.

Subijana Zunzunegui I. J. «El juez en la ejecución de las penas privativas de libertad», Revista Electrónica de Ciencia Penal y Criminología (en línea), 2005, núm. 07-11, p. 11:1 -11:20.

Vicente MARTínez R. «Sobre el expediente de acumulación de condenas». Revista Aranzadi de Derecho y Proceso Penal num.35/2014 parte Análisis Doctrinal Editorial Aranzadi, S.A.U., Cizur Menor. 2014.

\section{ANEXO DE JURISPRUDENCIA}

Tribunal Europeo de Derechos Humanos (Gran Sala). Caso Hirsi Jamaa $y$ otros contra Italia. Sentencia de 23 febrero 2012.

Tribunal Europeo de Derechos Humanos (Gran Sala). Caso Vinter y otros c. el Reino Unido, de 9 de julio de 2013

Tribunal Europeo de Derechos Humanos (Gran Sala). Caso Del Río Prada contra España. Sentencia de 21 octubre 2013.

Tribunal Europeo de Derechos Humanos (Sección tercera). Caso Arrózpide Sarasola y otros contra España. Sentencia de 23 de octubre de 2018. 
EsPaÑa. Tribunal Constitucional (Sala Primera).Sentencia núm. 67/1984, de 7 de junio.

España. Tribunal Constitucional (Sala Segunda). Sentencia núm.322/2005 de 12 diciembre.

EsPaÑa. Tribunal Constitucional (Sala Segunda). Sentencia núm.57/2008, de 28 de abril.

EsPaña. Tribunal Constitucional (Sala Primera).Sentencia núm.92/2012, de 7 de mayo.

EsPaña. Tribunal Constitucional (Pleno). Sentencia núm.35/2014 de 27 febrero.

España. Tribunal Constitucional (Sala Segunda). Sentencia núm.145/2014, de 22 de septiembre.

EsPaña. Tribunal Supremo (Sala de lo Penal, Sección $1^{\text {a }}$ ). Sentencia núm. 1129/2000, 27 de Junio.

EsPaÑa. Tribunal Supremo (Sala de lo Penal, Sección $1^{\text {a }}$ ). Sentencia núm. $651 / 2005$, de 20 de mayo.

EsPaÑa. Tribunal Supremo (Sala de lo Penal, Sección $1^{\text {a }}$ ). Sentencia núm. 579/2006, de 23 de mayo.

EsPaÑa. Tribunal Supremo (Sala de lo Penal, Sección $1^{\text {a }}$ ). Sentencia núm. 1391/2009, de 10 de diciembre

EsPaÑa. Tribunal Supremo (Sala de lo Penal, Sección $1^{\text {a }}$ ). Sentencia núm. 39/2012, de 29 de marzo.

EsPaña. Tribunal Supremo (Sala de lo Penal, Sección $1^{\text {a }}$ ). Sentencia núm. 473/2013 de 29 mayo.

EsPaÑa. Tribunal Supremo (Sala de lo Penal, Sección $1^{\text {a }}$ ). Sentencia núm. 707/2013, de 30 de septiembre .

EsPaña. Tribunal Supremo (Sala de lo Penal, Sección $1^{\text {a }}$ ). Sentencia núm. 14/2014, de 21 de enero.

EsPaÑa. Tribunal Supremo (Sala de lo Penal, Sección $1^{\text {a }}$ ). Sentencia núm. 172/2014, de 5 de marzo.

EsPaÑa. Tribunal Supremo (Sala de lo Penal, Sección $1^{\mathrm{a}}$ ). Sentencia núm. 186/2014, de 13 de marzo

EsPaÑa. Tribunal Supremo (Sala de lo Penal, Sección $1^{\text {a }}$ ). Sentencia núm. 408/2014, de 14 de mayo.

ESPAÑA. Tribunal Supremo (Sala de lo Penal, Sección $1^{\text {a }}$ ). Sentencia núm. 710/2014, de 7 noviembre.

EsPaÑa. Tribunal Supremo (Sala de lo Penal, Sección 1ª). Sentencia núm. 874/2014, de 27 de enero de 2015.

EsPaÑa. Tribunal Supremo (Sala de lo Penal, Sección $1^{\text {a }}$ ). Sentencia núm. 226/2015 de 17 abril. 
EsPaña. Tribunal Supremo (Sala de lo Penal, Sección 1ª). Sentencia núm. 367/2015, de 11 de junio.

EsPaÑa. Tribunal Supremo (Sala de lo Penal, Sección 1ª). Sentencia núm. 505/2015, de 20 de Julio.

EsPaña. Tribunal Supremo (Sala de lo Penal, Sección $1^{\mathrm{a}}$ ). Sentencia núm. $488 / 2015$, de 22 julio.

EsPaÑa. Tribunal Supremo (Sala de lo Penal, Sección $1^{\text {a }}$ ). Sentencia núm. 496/2015, de 24 de julio.

EsPaÑa. Tribunal Supremo (Sala de lo Penal, Sección 1ª). Sentencia núm. 139/2016, de 25 de febrero.

EsPaÑA. Tribunal Supremo (Sala de lo Penal, Sección $1^{\text {a }}$ ). Sentencia núm. 1592/2017, de 27 de abril.

EsPaña. Tribunal Supremo (Sala de lo Penal, Sección 1ª). Sentencia núm. 492/2019, de 16 de octubre .

EsPaÑa. Tribunal Supremo (Sala de lo Penal, Sección $1^{\mathrm{a}}$ ). Sentencia núm. $571 / 2019$, de 22 de noviembre .

EsPaña. Tribunal Supremo (Sala de lo Penal, Sección 1ª). Sentencia núm. 577/2019, de 26 de noviembre.

EsPaÑa. Tribunal Supremo (Sala de lo Penal, Sección $1^{\mathrm{a}}$ ). Sentencia núm.628/2019, de 18 de diciembre. 
